Full length article

\title{
AN ENHANCED WAVELET BASED METHOD FOR NUMERICAL SOLUTION OF HIGH ORDER BOUNDARY VALUE PROBLEMS
}

\author{
S. Haq', and M. Sohaib2,3, * \\ 1. Faculty of Engineering Sciences, GIK Institute, Topi 23660, KPK, Pakistan. \\ 2. Department of Mathematics and Statistics, Bacha Khan University, Charsadda, 24461, Pakistan \\ 3. Department of Mathematics, COMSATS University, Islamabad
}

\section{ABSTRACT}

The Legendre wavelet collocation method (LWCM) is suggested in this study for solving highorder boundary value problems numerically. Eighth, tenth, and twelfth-order examples are used as test problems to ensure that the technique is efficient and accurate. In comparison to other approaches, the numerical results obtained using LWCM demonstrate that the method's accuracy is very good. The results indicate that the method requires less computational effort to achieve better results.

KEYWORDS: Wavelet, Legendre wavelet, Legendre polynomials, Collocation points

*Corresponding author: (Email: msohaib@bkuc.edu.pk, Phone: 0092-346-9648868)

\section{INTRODUCTION}

The researchers are targeting ordinary differentials equation because of their importance in different areas of engineering, biomedical science, physics and mathematics. Due to their weight ordinary differential equation have been used in hydrodynamic and hydro magnetics stability, fluid mechanics[4], astronomy[1], introduction motors, beam and long wave theory [26]. An infinite layer of fluid with a certain incidence in rotation gives rise to instability/unsteadiness. The sixth order ordinary differential equation is modeled by the instability sets as an ordinary convection whereas eight order is in case of over stability. If heating of the same layer is under the influence magnetic field in direction of gravity the model is tenth order ordinary differential equation when instability sets as an ordinary convection and twelfth order ordinary differential equation in case of over stability $[4,1]$. In literature different procedures have been used to achieve the solution of ordinary differential equation of different orders. These techniques include the method of Homotopy analysis (HAM) [16, 26, 43], Variational literation (VIM) [15, 20, 24], Homotopy Perturbation (HPM) [8, 16, 20], Modified Decomposition (MDM) [34], Optimal Homotopy Asymptotic (OHAM) [13], Quintic B-spline (QBSM) [33], Non-Polynomial Spline (NPSM) [28], Eleven Degree Spline (EDSM) [29], Finite difference (FDM) [3], and Expfunction (EFM) [36 ] etc. For the study of $8^{\text {th }}$ order boundary value problem (BVP) HPM was used by golbabai and javidi[8], differential quadrature method (DQM) by liu and wu[18],OHAM by haq et al. [11], reproducing kernel space by Akram and Rehman [33,2]. Siddiqi and Akram utilized NPSM and EDSM for the solution of tenth order ordinary differential equation [28,29], Geng and li exercised VIM for the solution of tenth order boundary valve problems [6]. I. Ullah et el. made use of new iterative method while Wazwaz used MDM for the solution od tenth order BVPs [34,31]. The solution of twelfth order BVPs using DTM was 
computed by islam et el. [13]. Approximate solution of twelfth order BVPs were obtained via splines and HPM in [30,19]. Wavelet analysis has acquired popularity in recent years for numerical solutions of differential equations. The present study aims to formulate a Legendre wavelet collection method (LWCM)for high BVPS. The Legendre polynomials is used for the approximation of an unknown function and its derivatives. Legendre wavelet owes some important properties such as good interpolation, less computational cost, better accuracy with a smaller number of collection points. Motivated by these properties of the Legendre wavelet, we obtain approximate solutions of eight, tenth and twelfth order ordinary differential equation via LWCM in spectral mode was applied for the study of oscillatory type problems by Dizicheh. [5]. delay differential equation [32], advection problems [10], and lane-emden equation have been solved by LWCM. Authors in [25] have introduce operational matrix method using integration for Legendre wavelet. The same methodology has also been applied for solution of partial differential equation, integral and integro-differential equations, and fractional partial differential equations. Rest of the paper is organized as follows: in section 2 a short review of wavelet and Legendre wavelet is presented. Section 3 gives a briefs description of the proposed LWCM. In section 4 error analysis is given. In section 5 the proposed method is used for the approximate solution of same high order BVPs. Section 6 is devoted to the conclusion.

\section{WAVELET}

Wavelet arises and different applied sciences such as mathematics, quantum mechanics and engineering. Compact support, orthogonality, regularity, orthonormality, symmetry and good accuracy of approximation are the properties of the wavelets. A wavelet is a type of function that is made up of the dilation and translation of a single function known as the mother wavelet. [9]. Considered the following family of continuous wavelets

$$
\begin{gathered}
\mathcal{F}(x ; \alpha, \beta)=|\alpha|^{-\frac{1}{2}} \mathcal{F}\left(\alpha^{-1}(x-\beta)\right), \\
\alpha, \beta \in \mathbb{R}, \alpha \neq 0,
\end{gathered}
$$

where $a$ and $\beta$ are positively dilation and translation parameter which very continuously. Let us assume

$$
\alpha=\alpha_{0}^{-\delta}, \beta=m \beta_{0} \alpha_{0}^{\delta}, \alpha_{0}>1, \beta_{0}>0,
$$

where $\delta, m$ belong to $\mathbb{Z}^{+}$then Eq. (2.1) takes the form

$$
\mathcal{F}(x ; \delta, m)=\alpha^{\frac{\delta}{2}} \mathcal{F}\left(2^{\delta} x-m \beta_{0}\right) .
$$

In above equation $\mathcal{F}(x ; \delta, m)$ forms a wavelet basis for $L^{2}(\mathbb{R})$. In orthonormal basis $\alpha_{0}=2$ and $\beta_{0}=1$ and is given by

$$
\mathcal{F}(x ; \delta, m)=2^{\frac{\delta}{2}} \mathcal{F}\left(2^{\delta} x-m\right) .
$$

If $n=0,1, \ldots, N-1$ and $m=1,2, \ldots, 2^{\delta-1}$ then the Legendre wavelet are defined on the interval $[0,1)$ as follows [24]:

$$
\begin{aligned}
& \mathcal{F}(x ; m, n) \\
& =\left\{\begin{array}{cc}
(n+1)^{\frac{1}{2}} 2^{\frac{\delta}{2}} Q_{n}(k) & \text { for } 2^{1-\delta}(m-1) \leq x<2^{1-\delta} n \\
0, & \text { otherwise }
\end{array}\right.
\end{aligned}
$$

In the above definition $k=\left(2^{\delta} x+1-2 m\right)$, the coefficient $\left(n+\frac{1}{2}\right)^{\frac{1}{2}}$ is for orthonormality and $Q_{n}(*)$ represent Legendre polynomial of degree $n$ which can be computed with help

of the following recursion relation [37]

$Q_{0}(x)=1, \quad Q_{1}(x)=x$,

$(n+1) Q_{n+1}(x)-(2 n+1) x Q_{n}(x)+n Q_{n-1}(x)=0, \quad n=1,2,$. 


\section{DESCRIPTION OF THE TECHNIQUE}

In this section we represent the procedure how the method is applied to ODE to find its approximate solution. It should be emphasized that the ODE can be transformed into a system of algebraic equations (linear or nonlinear) using collocation points, and the solution can then be found from these equations. For this purpose, let us consider the following nth order initial for boundary value problem.

$$
\begin{gathered}
U^{(n)}(x)= \\
F\left(x, U(x), U^{\prime}(x), \ldots, U^{(n-1)}(x)\right), a^{1} \leq x \leq \\
a^{2},
\end{gathered}
$$

having the following initial (case i) or boundary (case ii, iii) conditions

Case i

$$
U^{(K-1)}\left(a^{1}\right)=\gamma_{k}, \quad k=1,2,3, \ldots, n
$$

Case ii

$$
U^{(K-1)}\left(a^{i}\right)=\gamma_{k}^{i}, i=1,2, k=1,2,3, \ldots, \frac{n}{2} .
$$

Case iii

$$
U^{(K-2)}\left(a^{i}\right)=\mathrm{X}_{k}^{i}, i=1,2, k=1,2,3, \ldots, \frac{n}{2} .
$$

In the above equation $\gamma k, \gamma_{k}^{i}, \mathrm{X}_{k}^{i}$, are known constant and $U$ is known function. Now the function $U(x)$ can be approximated by the Legendre wavelet over interval [0, 1) [16] and is given as follows:

$$
U(x)=\sum_{i=1}^{\infty} \sum_{j=0}^{\infty} \beta_{i}^{j} \mathcal{F}{ }_{i}^{j}(x)
$$

where $\beta_{i}^{j}$ are unknown constants to be calculated. In actual computation Eq. (3.5) is written

$$
U(x)=\sum_{i=1}^{2^{\delta-1}} \sum_{j=0}^{M-1} \beta_{i}^{j} \mathcal{F}{ }_{i}^{j}(x),
$$

which can be written as

$$
U(x)=B \mathcal{F}(x),
$$

where $B$ and $\mathcal{F}$ are respectively row and Colum matrices defined as follow:
$B=\left[\beta_{1}^{0}, \beta_{1}^{1}, \beta_{1}^{1}, \ldots, \beta_{1}^{M-1}, \beta_{2}^{0}, \beta_{2}^{1}, \ldots, \beta_{2}^{M-1}, \ldots, \beta_{2^{k-1}}^{0}, \beta_{2^{k-1}}^{1}, \ldots, \beta_{2^{k-1}}^{M-1}\right]$, $\mathcal{F}(x)=\left[\mathcal{F}_{1}^{0}(x), \mathcal{F}_{1}^{1}(x), \mathcal{F}_{1}^{M-1}(x), \mathcal{F}_{2}^{0}(x), \ldots, \mathcal{F}_{2}^{M-1}(x), \ldots, \mathcal{F}_{2^{k-1}}^{0}(x), \ldots, \mathcal{F}_{2^{k-1}}^{M-1}(x)\right]^{T}$. From Eq. (3.7) we can write

$$
U^{i}(x)=B \mathcal{F}^{i}(x), i=1,2, \ldots, n \text {. }
$$

Using Eq. (3.7) and (3.8) in Eq. (3.1)-(3.4) implies that

$$
\begin{aligned}
& B \mathcal{F}^{n}(x)=\mathcal{F}\left(x, B \mathcal{F}(x), B \mathcal{F}^{\prime}(x), \ldots, B \mathcal{F}^{(n-1)}(x)\right) . \\
& B \mathcal{F}^{(k-1)}\left(a^{1}\right)=\gamma k, k=1,2,3, \ldots, n . \\
& \quad B \mathcal{F}^{(k-1)}\left(a^{i}\right)=\gamma_{k}^{i}, i=1,2, k=1,2,3, \ldots, \frac{n}{2} . \\
& B \mathcal{F}^{(k-1)}\left(a^{i}\right)=X_{k}^{i}, i=1,2, \\
& k=1,2,3, \ldots, \frac{n}{2} .
\end{aligned}
$$

From Eq. (3.6) there are $M 2^{k-1}$ constants to be determined. The calculation of these constants needs $M 2^{k-1}$ equations. Now $n$ number of equations can be derived from Eq. (3.10) or (3.11) or (3.12) and rest of $M 2^{k-1}-n$ equations can be obtained from Eq. (3.9) using the collocation points and are given by

$$
B \mathcal{F}^{n}\left(x_{j}\right)=\mathcal{F}\left(x_{j}, B \mathcal{F}\left(x_{j}\right), B \mathcal{F}^{\prime}\left(x_{j}\right), \ldots, B \mathcal{F}^{n-1}\right.
$$

where

$$
x_{j}=\frac{j-0.5}{2^{k} M-n^{\prime}}, j=1,2, \ldots, 2^{k-1} M-n .
$$

Therefore Eq. (3.13) coupled with Eq. (3.10) or (3.11) or (3.12) give system of $2^{k-1} M$ equations and one can find the value of the unknown constants $\beta_{i}^{j}$. Using the value of $\beta_{i}^{j}$ in Eqs. (3.6) will give the required solution.

\section{ERROR ANALYSIS}

Theorem (Sohaib and Haq [7]): Assume that $U(x)$ and $U^{*}(x)$ be the exact approximate solution of Eq. (3.1) respectively. Moreover, also assume that $\left|U^{\prime}(x)\right| \leq B_{1}$ and $\left|U^{\prime \prime}(x)\right| \leq B_{2}$, where $B_{1}$ and $B_{2}$ are constant than

$$
\|E\|^{2} \leq \sum_{n=2^{k-1}}^{\infty} \sum_{m=M}^{\infty} \frac{3 B_{2}^{2}}{2 n^{5}(2 m-3)^{4}} .
$$

\section{NUMERICAL EXAMPLES}

In this section the proposed method (LWCM) is used to find the approximate solution of linear 
and nonlinear eight, tenth, and twelfth order boundary value problems. To determine the technique's efficacy, the results are compared to those obtained using other methods available in the literature.

\subsection{EIGHT ORDER ODES}

Example 1: Let us consider the following linear eight order boundary value problem [26]

$$
\begin{aligned}
U^{(8)}(x)-U(x)= & -8 e^{x}, \quad 0<x \\
& <1,
\end{aligned}
$$

with boundary condition

$$
\begin{aligned}
U^{(j)}(0)=1-j, \quad U^{(k)}(1)=-k e, \\
j=0,1, \ldots, 5 \text { and } k=1,2 .
\end{aligned}
$$

The exact solution of problem (5.1) is given by

$$
U(x)=(1-x) e^{x} .
$$

Solution: Taking $\delta=1$ and $M=17$, Eq.

(3.6) become

$$
U(x)=\sum_{J=0}^{16} \beta_{1}^{j} \mathcal{F}_{1}^{j}(x)=B \mathcal{F}(X),
$$

where $B$ and $\mathcal{F}$ are

$$
\begin{aligned}
& B=\left[\beta_{1}^{0}, \beta_{1}^{1}, \ldots, \beta_{1}^{16}\right] \\
& \mathcal{F}(x)=\left[\mathcal{F}_{1}^{0}, \mathcal{F}_{1}^{1}, \ldots, \mathcal{F}_{1}^{16}\right]^{T}
\end{aligned}
$$

Using Eq. (5.1) and boundary conditions we obtain

$$
B \mathcal{F}^{(8)}(x)-B \mathcal{F}(x)=-8 e^{x}
$$

and

$$
\begin{aligned}
& B \mathcal{F}^{(j)}(0)=1-j, \quad B \mathcal{F}^{(k)}(1) \\
&=-K e, \\
& j=0,1,2, \ldots, 5 \quad \text { and } \quad K=1,2 .
\end{aligned}
$$

At $x=x_{j}$ (see Eq. (3.14) the above

equation becomes

$$
\begin{gathered}
B \mathcal{F}^{8}\left(x_{j}\right)-B \mathcal{F}\left(x_{j}\right)=-8 e^{x_{j}}, \\
j=1,2, \ldots, 9
\end{gathered}
$$

Where $x_{j}$ are the collection points given by Eq. (3.14). Eq. (5.4) together with the boundary conditions give system of seventeen equations in seventeen unknowns. Solving the system so obtained the unknown is given as follow:

$\beta_{1}^{0}=7.1828 \times 10^{-1}, \beta_{1}^{1}=-2.682 \times 10^{-1}, \quad \beta_{1}^{2}$

$$
=-9.6049 \times 10^{-2} \text {, }
$$

$$
\begin{gathered}
\beta_{1}^{3}=-1.3310 \times 10^{-2}, \quad \beta_{1}^{4}=-1.1655 \times 10^{-3}, \\
\beta_{1}^{5}=-7.5008 \times 10^{-5}, \beta_{1}^{6}=-3.82352 \times 10^{-6}, \\
\beta_{1}^{7}=-1.61514 \times 10^{-7}, \quad \beta_{1}^{8}=-5.82777 \times 10^{-9}, \\
\beta_{1}^{9}=-1.83571 \times 10^{-10}, \quad \beta_{1}^{10}=-5.13164 \times 10^{12}, \\
\beta_{1}^{11}=-1.28957 \times 10^{-13}, \quad \beta_{1}^{12}=-2.94351 \times 10^{15}, \\
\beta_{1}^{13}=-6.15476 \times 10^{-17}, \quad \beta_{1}^{14}=-1.18679 \times 10^{-18}, \\
\beta_{1}^{15}=-2.11898 \times 10^{-20}, \quad \beta_{1}^{16} \\
=-3.90587 \times 10^{-22} .
\end{gathered}
$$

Putting value in $\beta_{1}^{j}$ in Eq. (5.2), the solution of the problem (5.1) is

$$
\begin{aligned}
& U(x)=1-2.22 \times 10^{-16} x-0.5 x^{2}-0.33 x^{3}-0.125 x^{4}-0.03 x^{5} \\
& -0.007 x^{6}-0.001 x^{7}-0.0002 x^{8}-0.00002 x^{9}-2.84 \times 10^{-6} x^{10} \\
& -2.51 \times 10^{-7} x^{11}-2.3 \times 10^{-8} x^{12}-1.91 \times 10^{-9} x^{13} \\
& -1.54 \times 10^{10} x^{14}-8.57 \times 10^{-12} x^{15}-1.23 \times 10^{-12} x^{16} .
\end{aligned}
$$

The result obtained and comparison with the method in $[2,8,12]$ are given in table 1. From the table it can be observed that the result got using LWCM are more accurate than that other method. As we increase the value of the $M$ the accuracy become better. This show accuracy of the present technique.

Example 2: Let us consider another eight order BVP [33] given as follow:

$$
\begin{gathered}
U^{(8)}(x)+x U(x)=-e^{x}\left(48+15 x+x^{3}\right), \\
0<x<1,
\end{gathered}
$$

with the following boundary conditions

$$
\begin{gathered}
U^{k}(0)=k-(2-k) \\
U^{k}(1)=-k^{2} e \text { for } k=0,1,2,3 .
\end{gathered}
$$

The theoretical solution of problem (5.5) -(5.6) is

$$
U(x)=x(1-x) e^{x} .
$$

Solution: As in example 1 when $\delta=1$ and $M=17$ then Eq. (3.6) transform to Eq. (5.2) the use of Eu. (5.2) convert the Eq. (5.5) and (5.6) to the following equations

$$
B \mathcal{F}^{8}(x)+x B \mathcal{F}(x)=-e^{x}\left(48+15+x^{3}\right),
$$

and

$$
\begin{gathered}
B \mathcal{F}^{(k)}(0)=k(2-k) \\
B \mathcal{F}^{(k)}(1)=-K^{2} e, \quad k=0,1,3 .
\end{gathered}
$$

At the collection points $x_{j}$ (see Eq. (3.14)), the Eq. (5.8) yields 
$B \mathcal{F}^{(8)}\left(X_{J}\right)+x B \mathcal{F}\left(x_{j}\right)=-e^{x_{j}}\left(48+15 x_{j}+x_{j}^{3}\right), j=1,2, \ldots, 9$

Eq. (5.10) together with Eq. (5.9) gives seventeen equations. Solving these equations gives the constant given by

$$
\begin{gathered}
\beta_{1}^{0}=2.817 \times 10^{-1}, \beta_{1}^{1}=4.84503 \times 10^{-2}, \\
\beta_{1}^{2}=-1.20648 \times 10^{-1}, \beta_{1}^{3}=-3.13013 \times 10^{-2}, \\
\beta_{1}^{4}=-3.95534 \times 10^{-3}, \quad \beta_{1}^{5}=-3.31312 \times 10^{-4}, \\
\beta_{1}^{6}=-2.07696 \times 10^{-5}, \quad \beta_{1}^{7}=-1.04055 \times 10^{-6}, \\
\beta_{1}^{8}=-4.34174 \times 10^{-8}, \beta_{1}^{9}=-1.55226 \times 10^{-9}, \\
\beta_{1}^{10}=-4.85482 \times 10^{11}, \quad \beta_{1}^{11}=-1.34945 \times 10^{-12}, \\
\beta_{1}^{12}=-3.37545 \times 10^{14}, \quad \beta_{1}^{13}=-7.67494 \times 10^{-16}, \\
\beta_{1}^{14}=-1.59956 \times 10^{-17}, \beta_{1}^{15}=-3.08249 \times 10^{-19}, \\
\beta_{1}^{16}=-5.50016 \times 10^{-21},
\end{gathered}
$$

Substituting the value of the unknown $\beta_{1}^{j}$ in Eq. (5.2) the solution of the problem (5.8) -(5.9) can be obtained. In table 2 the absolute error using the proposed method is compared with those of the method in $[2,27,14]$ available in the literature. The results obtained using the proposed method are clearly superior to those obtained using the other methods, as shown in the table. The accuracy is increase as we increase the value of $M$. This show that the LWCM can be applied to the differential equation for better results.

Example 3: Let us consider another eight-order boundary value problem taken from [33] and is given below:

$$
\begin{aligned}
U^{8}(x)+U^{7}(x)+2 U^{(6)}(x) & +2 U^{(5)}(x)+2 U^{(4)}(x)+2 U^{(3)}(x) \\
+2 U^{\prime \prime}(x)+U^{\prime}(x) & +U(x) \\
& =14 \cos -16 \sin -4 x \sin x, \quad 0<x \\
< & 1(5.10)
\end{aligned}
$$

with the boundary condition

$$
\begin{gathered}
U^{(k)}(0)=\frac{2 k^{3}-3 k^{2}-2 k}{3} \\
U^{(k)}(1)=\left(k+2 k^{2}-k^{3}\right) \sin 1-(4 k \\
\left.-5 k^{2}+k^{3}\right) \cos 1, \\
k=0,1,2,3 .
\end{gathered}
$$

The exact solution of the problem (5.10) $(5.11)$ is

$$
U(x)=\left(x^{2}-1\right) \sin x .
$$

Using $\delta=1$ and $M=17 \mathrm{Eq}$. (3.6) takes the form given by Eq. (5.4) and plugging the value from Eq. (5.4) into Eqs. (5.10) -(5.11) the following can be obtained

$$
\begin{gathered}
B\left\{\mathcal{F}^{(8)}(x)+\mathcal{F}^{(7)}(x)+2 \mathcal{F}^{(6)}(x)+2 \mathcal{F}^{(5)}(x)+2 \mathcal{F}^{(4)}(x)\right. \\
\left.+2 \mathcal{F}^{(3)}(x)+2 \mathcal{F}^{(2)}(x)+\mathcal{F}^{\prime}(x)+\mathcal{F}(x)\right\} \\
=14 \cos -16 \sin -4 x \sin x, \\
B \mathcal{F}^{(k)}(0)=\frac{2 K^{3}-3 K^{2}-2 K}{3}, \\
B \mathcal{F}^{(k)}(1)=\left(k+2 k^{2}-k^{3}\right) \sin 1-(4 k \\
-5 k^{2} \\
+k^{3)} \cos 1, \\
k=0,1,2,3 .
\end{gathered}
$$

Utilizing the collection points $x_{k}$ (given by Eq. (3.14)) in Eq. (5.12) we arrived at

$$
\begin{aligned}
& B\left\{\mathcal{F}^{(8)}\left(x_{k}\right)+\mathcal{F}^{(7)}\left(x_{k}\right)+2 \mathcal{F}^{(6)}\left(x_{k}\right)+2 \mathcal{F}^{(5)}\left(x_{k}\right)+2 \mathcal{F}^{(4)}\left(x_{k}\right)\right. \\
& \left.+2 \mathcal{F}^{(3)}\left(x_{k}\right)+2 \mathcal{F}^{(2)}\left(x_{k}\right)+\mathcal{F}^{(\prime)}\left(x_{k}\right)+\mathcal{F}\left(x_{k}\right)\right\} \\
& =14 \cos x_{k}-16 \sin x_{k}-4 k_{x} \sin x_{k}
\end{aligned}
$$

Eq. (5.14) and (5.13) generates a system of seventeen equation in seventeen unknowns which can be easily solved for the unknown $B_{1,}^{J} \quad \mathrm{~J}=0,1,2, \ldots, 16$. The value of these unknowns is computed, and the required solution has been obtained from (5.2). The absolute error has been computed with those of quintic B-spline method (QBSM) available in the literature and are tabulated in table 3. From the table it is straight forward that the result of the present method is very good as compared to other technique.

Example 4: Let us consider the following nonlinear eight order BVP [1 1]

$$
U^{(8)}(x)=e^{-x} U^{2}(x), \quad 0<x<1
$$

Subject to the boundary condition

$$
\begin{aligned}
U^{(k)}(0)=1 \quad U^{(k)}(1) & =e_{x,} \quad k \\
& =0,2,4,6 .
\end{aligned}
$$

Exact solution of the problem (5.15) $-(5.16)$ is 


$$
U(x)=e^{x} .
$$

Using $\delta=1$ and $M=17$ in Eq. (3.6) which becomes

$$
U(x)=\sum_{j=o}^{16} \beta_{1}^{j} \mathcal{F}_{1}^{j}(x)=B \mathcal{F}(x)
$$

The use of Eq. (5.17) in Eq. (5.15) and (5.16) gives

$$
\begin{gathered}
B \mathcal{F}^{(8)}(x)=e^{-x} B^{2} \mathcal{F}^{2}(x), \\
B \mathcal{F}^{(k)}(0)=1, \quad B \mathcal{F}^{(k)}(1)=e \\
k=0,2,4,6 .
\end{gathered}
$$

Eq. (5.18) at $x=x_{j}$ (see Eq. (3.14)) gives the following system

$$
\begin{gathered}
B \mathcal{F}^{(8)}\left(x_{j}\right)=e^{-x_{j}} B^{2} \mathcal{F}^{(2)}\left(x_{j}\right), \\
j=1,2, \ldots, 9 .
\end{gathered}
$$

Value of seventeen unknown $\beta_{1}^{j}$ 's has been computed from the system of seventeen equations given by Eqs. (5.19) and (5.20). The solution of the problem has been obtained from the substitution of $\beta_{1}^{j}$ in Eq. (5.17). The results, absolute error and comparison with the method in $[2,21,12]$ are given in table 4 . From the table the result of the present method is very good as compared to the other method of literature. The increase in the value of $M$ gives us more accurate results.

\subsection{TENTH ORDER ODES}

In this section the examples of tenth order ODEs have been chosen for study. The method under consideration is applied to check the applicability and the accuracy of the technique.

Example 5: Taking the linear tenth order ODEs [23]

$U^{(10)}(x)+5 U(x)=10 \cos x+4(1-x) \sin x, 0<x<1,(5.21)$ with the boundary conditions

$$
\begin{aligned}
U^{(2 k)}(\eta)=(-1)^{K+1} 2 k \cos \eta, & \\
\eta=0,1 \quad k & =0,1,2,3,4 .(5.22)
\end{aligned}
$$

Exact solution of the problem is given below

$$
U(x)=(x-1) \sin x .
$$

The problem has been solved using the same methodology as discussed in the previous examples. Absolute errors for differential values of $M$ have been calculated and are shown in table 5. From table the results obtained are very close to exact solution. Furthermore, accuracy can be enhanced by increasing the value of $M$.

Example 6: Taking nonlinear BVP of order ten [31]

$U^{(10)}(x)=e^{-x} U^{2}(x), \quad 0<x<1$,

subject to the following boundary condition $U^{2 k}(\eta)=e^{\eta}, \quad \eta=0,1, \quad k=0,1,2,3,4$.

The exact solution is $U(x)=e^{x}$. For the solution of this problem the proposed technique is applied when $\delta=1, \mathrm{M}=19,17,15,13,11$.

The obtained results are tabulated in table 6 and are compared with those of new iterative method (NIM) [31]. From the table the result of LWCM is better than that of NIM.

\subsection{TWELFTH ORDER ODES}

Example 7: Consider twelfth order ODE [17] $U^{12}(x)+x U(x)=-\left(120+23 x+x^{3}\right) e^{x}, \quad 0<x<1$,

coupled with the following boundary condition

$$
U^{(k)}(\eta)=k(2(1-\eta)-k) e^{\eta}, \quad \eta=0,1, \quad k=0,1,2,3,4,5 .
$$

Exact solution is $U(x)=x(1-x) e^{x}$. The same procedure as discussed in previous example with $\delta=1$ and $M=18,16,14$ is 
implemted here also. The obtained numerical results and comparison of the error with DTM [13] is tabulated in table 7 . Here again the results are more accurate than those of DTM.

Example 8: Another example of twelfth order BVP of the form [22] $U^{(12)}(x)=2 e^{x} U^{2}(x)+U^{(3)}(x), \quad 0<x<1$,

subject to the boundary conditions $U^{(2 k)}(\eta)=e^{-\eta}, \quad \eta=0,1, \quad k=0,1,2,3,4,5$.
The exact solution of the problems is $U(x)=$ $e^{-x}$. The solution of the problems has been obtained with the help of the same method taking $\delta=1$ and $M=18,16,14$. The results so obtained are posted in the table 8 and are compared with the results of DTM [13] which are available in literature. Again, the results with LWCM are better.

Table 1: Absolute error comparison of LWCM when k=1

\begin{tabular}{|c|c|c|c|c|c|c|c|}
\hline$x$ & LWCM & & & RKS [2] & & HPM [8] & VIM [12] \\
\hline & $M=13$ & $M=15$ & $M=17$ & $n=7$ & $n=30$ & $N=7$ & \\
\hline 0.25 & $1.38 \mathrm{E}-13$ & $3.33 \mathrm{E}-16$ & $2.22 \mathrm{E}-16$ & $3.03 \mathrm{E}-10$ & $7.50 \mathrm{E}-12$ & $2.16 \mathrm{E}-09$ & $4.58 \mathrm{E}-09$ \\
\hline 0.50 & $4.78 \mathrm{E}-12$ & $6.77 \mathrm{E}-15$ & $0.00 \mathrm{E}-00$ & 7.73E-09 & $2.35 \mathrm{E}-10$ & $1.16 \mathrm{E}-07$ & $9.84 \mathrm{E}-09$ \\
\hline 0.75 & $1.91 \mathrm{E}-11$ & $2.55 \mathrm{E}-14$ & $2.22 \mathrm{E}-16$ & $3.12 \mathrm{E}-08$ & $1.08 \mathrm{E}-09$ & $1.05 \mathrm{E}-06$ & $1.10 \mathrm{E}-05$ \\
\hline 1.0 & $2.63 \mathrm{E}-11$ & $3.48 \mathrm{E}-14$ & $4.57 \mathrm{E}-16$ & $4.40 \mathrm{E}-08$ & $1.59 \mathrm{E}-09$ & $4.22 \mathrm{E}-06$ & $1.86 \mathrm{E}-04$ \\
\hline
\end{tabular}

Table 2: Absolute error comparison of LWCM when $k=1$

\begin{tabular}{|c|c|c|c|c|c|c|c|c|}
\hline \multirow[t]{2}{*}{$x_{i}$} & LWCM & & & & & RKS [2] & Method in & Method in \\
\hline & $M=17$ & $M=15$ & $M=13$ & $M=11$ & $M=9$ & $N=10$ & & \\
\hline 0.1 & $1.25 \mathrm{E}-16$ & 8.33E-17 & 8.13 E-14 & 8.72 E-11 & 5.57 E-09 & $1.63 \mathrm{E}-10$ & $5.62 \mathrm{E}-10$ & 3.73 E-09 \\
\hline 0.2 & $1.67 \mathrm{E}-16$ & $3.61 \mathrm{E}-16$ & $4.33 \mathrm{E}-13$ & $6.70 \mathrm{E}-10$ & 3.57 E-08 & 1.63 E-09 & 4.88 E-09 & $6.61 \mathrm{E}-09$ \\
\hline 0.3 & $5.55 \mathrm{E}-17$ & 4.44 E-16 & $4.90 \mathrm{E}-13$ & 1.24 E-09 & $4.56 \mathrm{E}-08$ & 4.90 E-09 & $1.37 \mathrm{E}-08$ & $2.33 \mathrm{E}-08$ \\
\hline 0.4 & $5.55 \mathrm{E}-17$ & $2.78 \mathrm{E}-16$ & $1.19 \mathrm{E}-13$ & $6.53 \mathrm{E}-10$ & 2.79 E-08 & 8.46 E-09 & $2.29 \mathrm{E}-08$ & 5.17 E-08 \\
\hline 0.5 & 0.00000 & 0.000000 & $2.55 \mathrm{E}-13$ & 1.16 E-09 & $1.60 \mathrm{E}-07$ & $1.01 \mathrm{E}-09$ & 2.71 E-08 & $9.76 \mathrm{E}-08$ \\
\hline
\end{tabular}




\begin{tabular}{lllllllll}
0.6 & $2.22 \mathrm{E}-16$ & $2.78 \mathrm{E}-16$ & $5.89 \mathrm{E}-13$ & $2.47 \mathrm{E}-09$ & $2.47 \mathrm{E}-07$ & $8.68 \mathrm{E}-09$ & $2.38 \mathrm{E}-08$ & $1.78 \mathrm{E}-06$ \\
0.7 & $3.33 \mathrm{E}-16$ & $3.33 \mathrm{E}-16$ & $8.34 \mathrm{E}-13$ & $2.31 \mathrm{E}-09$ & $2.12 \mathrm{E}-07$ & $5.15 \mathrm{E}-09$ & $2.38 \mathrm{E}-08$ & $4.12 \mathrm{E}-06$ \\
0.8 & $3.33 \mathrm{E}-16$ & $2.78 \mathrm{E}-16$ & $5.89 \mathrm{E}-13$ & $1.03 \mathrm{E}-09$ & $9.44 \mathrm{E}-08$ & $1.76 \mathrm{E}-09$ & $5.54 \mathrm{E}-09$ & $1.83 \mathrm{E}-04$ \\
\hline
\end{tabular}

Table 3: Absolute error comparison of LWCM when $k=1$

\begin{tabular}{|c|c|c|c|c|c|c|}
\hline$x_{i}$ & LWCM & & & & & QBSM [33] \\
\hline & $M=17$ & $M=15$ & $M=13$ & $M=11$ & $M=9$ & \\
\hline 0.1 & $2.25 \mathrm{E}-15$ & $7.77 \mathrm{E}-16$ & 4.37E-14 & 4.94E-11 & 3.99E-09 & $2.68 \mathrm{E}-07$ \\
\hline 0.2 & $1.97 \mathrm{E}-15$ & $1.55 \mathrm{E}-15$ & $2.31 \mathrm{E}-13$ & $3.84 \mathrm{E}-10$ & $2.86 \mathrm{E}-08$ & $9.24 \mathrm{E}-07$ \\
\hline 0.3 & $1.33 \mathrm{E}-15$ & $2.11 \mathrm{E}-15$ & $2.64 \mathrm{E}-13$ & 7.45E-10 & $5.22 \mathrm{E}-08$ & $1.94 \mathrm{E}-06$ \\
\hline 0.4 & $2.78 \mathrm{E}-16$ & $2.33 \mathrm{E}-15$ & $7.77 \mathrm{E}-14$ & $5.20 \mathrm{E}-10$ & 3.40E-08 & $3.52 \mathrm{E}-06$ \\
\hline 0.5 & $1.05 \mathrm{E}-15$ & $2.44 \mathrm{E}-15$ & $1.08 \mathrm{E}-13$ & $3.06 \mathrm{E}-10$ & 2.37E-08 & 4.44E-06 \\
\hline 0.6 & $2.28 \mathrm{E}-15$ & $2.55 \mathrm{E}-15$ & $2.73 \mathrm{E}-13$ & $1.02 \mathrm{E}-09$ & 7.33E-08 & $4.68 \mathrm{E}-06$ \\
\hline 0.7 & $2.94 \mathrm{E}-15$ & $3.22 \mathrm{E}-15$ & $3.94 \mathrm{E}-13$ & $1.01 \mathrm{E}-09$ & 7.36E-08 & 4.26E-06 \\
\hline 0.8 & $3.33 \mathrm{E}-15$ & $4.11 \mathrm{E}-15$ & $2.78 \mathrm{E}-13$ & $4.57 \mathrm{E}-10$ & 3.49E-08 & $2.86 \mathrm{E}-06$ \\
\hline 0.9 & $3.16 \mathrm{E}-15$ & $5.30 \mathrm{E}-15$ & 4.77E-14 & $5.46 \mathrm{E}-11$ & $4.48 \mathrm{E}-09$ & $1.28 \mathrm{E}-06$ \\
\hline
\end{tabular}

Table 4: Absolute error comparison of LWCM when $k=1$

\begin{tabular}{|c|c|c|c|c|c|c|c|c|c|}
\hline$x_{i}$ & LWCM & & & & & RKS [2] & & Method in [21] & Method in [14] \\
\hline & $M=17$ & $M=15$ & $M=13$ & $M=11$ & $M=9$ & $n=10$ & $n=20$ & & \\
\hline 0.1 & 0.000000 & 0.000000 & $2.22 \mathrm{E}-16$ & $3.77 \mathrm{E}-15$ & $1.58 \mathrm{E}-13$ & 7.53E-08 & $1.61 \mathrm{E}-08$ & $1.27 \mathrm{E}-05$ & $1.91 \mathrm{E}-07$ \\
\hline 0.2 & 0.000000 & $2.22 \mathrm{E}-16$ & $5.11 \mathrm{E}-15$ & $8.84 \mathrm{E}-13$ & $3.97 \mathrm{E}-11$ & $1.43 \mathrm{E}-07$ & 3.07 E-08 & $2.43 \mathrm{E}-05$ & $1.25 \mathrm{E}-07$ \\
\hline 0.3 & $2.22 \mathrm{E}-16$ & $2.22 \mathrm{E}-16$ & $1.12 \mathrm{E}-13$ & $2.04 \mathrm{E}-11$ & $10.00 \mathrm{E}-10$ & $1.96 \mathrm{E}-07$ & $4.23 \mathrm{E}-08$ & $3.35 \mathrm{E}-05$ & 7.25E-08 \\
\hline 0.4 & 0.000000 & $2.22 \mathrm{E}-15$ & $9.45 \mathrm{E}-13$ & $1.84 \mathrm{E}-10$ & $9.79 \mathrm{E}-09$ & $2.31 \mathrm{E}-07$ & 4.97 E-08 & $3.94 \mathrm{E}-05$ & $4.85 \mathrm{E}-08$ \\
\hline 0.5 & 0.000000 & $1.15 \mathrm{E}-14$ & $4.82 \mathrm{E}-12$ & $9.93 \mathrm{E}-10$ & $5.72 \mathrm{E}-08$ & $2.42 \mathrm{E}-07$ & $5.23 \mathrm{E}-08$ & $4.16 \mathrm{E}-05$ & 2.91E-07 \\
\hline 0.6 & $4.44 \mathrm{E}-16$ & $4.31 \mathrm{E}-14$ & $1.79 \mathrm{E}-11$ & $3.86 \mathrm{E}-09$ & $2.41 \mathrm{E}-07$ & $2.30 \mathrm{E}-07$ & 4.98 E-08 & $3.96 \mathrm{E}-05$ & $7.80 \mathrm{E}-08$ \\
\hline 0.7 & $4.44 \mathrm{E}-16$ & $1.28 \mathrm{E}-13$ & $5.40 \mathrm{E}-11$ & $1.20 \mathrm{E}-08$ & $8.08 \mathrm{E}-07$ & $1.95 \mathrm{E}-07$ & 4.24 E-08 & $3.38 \mathrm{E}-05$ & $1.11 \mathrm{E}-07$ \\
\hline 0.8 & 4.44E-16 & $3.29 \mathrm{E}-13$ & $1.39 \mathrm{E}-10$ & $3.17 \mathrm{E}-08$ & $2.30 \mathrm{E}-06$ & $1.42 \mathrm{E}-07$ & $3.08 \mathrm{E}-08$ & $2.45 \mathrm{E}-05$ & $1.71 \mathrm{E}-07$ \\
\hline
\end{tabular}


Table 5: Absolute error comparison of LWCM when $k=1$

\begin{tabular}{|c|c|c|c|c|c|}
\hline$x_{i}$ & LWCM & & & & \\
\hline & $M=19$ & $M=17$ & $M=15$ & $M=13$ & $M=11$ \\
\hline 0.1 & $2.36 \mathrm{E}-16$ & $1.03 \mathrm{E}-15$ & $8.77 \mathrm{E}-13$ & 7.32E-10 & $1.05 \mathrm{E}-06$ \\
\hline 0.2 & $1.94 \mathrm{E}-16$ & $1.50 \mathrm{E}-15$ & $1.68 \mathrm{E}-12$ & $1.40 \mathrm{E}-09$ & $2.00 \mathrm{E}-06$ \\
\hline 0.3 & $2.22 \mathrm{E}-16$ & $1.92 \mathrm{E}-15$ & $2.34 \mathrm{E}-12$ & $1.94 \mathrm{E}-09$ & $2.76 \mathrm{E}-06$ \\
\hline 0.4 & $1.94 \mathrm{E}-16$ & $2.08 \mathrm{E}-15$ & $2.78 \mathrm{E}-12$ & 2.30E-09 & $3.26 \mathrm{E}-06$ \\
\hline 0.5 & $1.94 \mathrm{E}-16$ & $2.25 \mathrm{E}-15$ & $2.97 \mathrm{E}-12$ & $2.45 \mathrm{E}-09$ & $3.43 \mathrm{E}-06$ \\
\hline 0.6 & $1.39 \mathrm{E}-16$ & $2.14 \mathrm{E}-15$ & $2.86 \mathrm{E}-12$ & $2.35 \mathrm{E}-09$ & $3.27 \mathrm{E}-06$ \\
\hline 0.7 & $1.11 \mathrm{E}-16$ & $1.80 \mathrm{E}-15$ & $2.46 \mathrm{E}-12$ & $2.02 \mathrm{E}-09$ & $2.79 \mathrm{E}-06$ \\
\hline 0.8 & $5.55 \mathrm{E}-17$ & $1.22 \mathrm{E}-15$ & $1.81 \mathrm{E}-12$ & $1.48 \mathrm{E}-09$ & $2.03 \mathrm{E}-06$ \\
\hline 0.9 & $1.39 \mathrm{E}-17$ & $4.86 \mathrm{E}-16$ & $9.57 \mathrm{E}-13$ & $7.81 \mathrm{E}-10$ & $1.07 \mathrm{E}-06$ \\
\hline
\end{tabular}

Table 6: Absolute error comparison of LWCM when $k=1$

\begin{tabular}{|c|c|c|c|c|c|c|}
\hline$x_{i}$ & LWCM & & & & & NIM [31] \\
\hline & $M=19$ & $M=17$ & $M=15$ & $M=13$ & $M=11$ & \\
\hline 0.1 & $6.66 \mathrm{E}-16$ & $6.66 \mathrm{E}-16$ & $9.50 \mathrm{E}-13$ & $9.09 \mathrm{E}-11$ & $1.62 \mathrm{E}-07$ & 4.11E-09 \\
\hline 0.2 & $1.78 \mathrm{E}-15$ & $1.55 \mathrm{E}-15$ & $1.84 \mathrm{E}-12$ & $1.75 \mathrm{E}-10$ & 3.09E-07 & $7.81 \mathrm{E}-09$ \\
\hline 0.3 & $2.22 \mathrm{E}-15$ & $1.77 \mathrm{E}-15$ & $2.59 \mathrm{E}-12$ & $2.45 \mathrm{E}-10$ & $4.28 \mathrm{E}-07$ & $1.08 \mathrm{E}-08$ \\
\hline 0.4 & $3.11 \mathrm{E}-15$ & $2.89 \mathrm{E}-15$ & $3.13 \mathrm{E}-12$ & $2.94 \mathrm{E}-10$ & $5.06 \mathrm{E}-07$ & $1.27 \mathrm{E}-08$ \\
\hline 0.5 & $3.11 \mathrm{E}-15$ & $2.66 \mathrm{E}-15$ & $3.39 \mathrm{E}-12$ & $3.17 \mathrm{E}-10$ & $5.35 \mathrm{E}-07$ & $1.33 \mathrm{E}-08$ \\
\hline 0.6 & $3.11 \mathrm{E}-15$ & $2.66 \mathrm{E}-15$ & $3.32 \mathrm{E}-12$ & $3.08 \mathrm{E}-10$ & $5.12 \mathrm{E}-07$ & $1.27 \mathrm{E}-08$ \\
\hline 0.7 & $2.66 \mathrm{E}-15$ & $2.22 \mathrm{E}-15$ & $2.90 \mathrm{E}-12$ & $2.68 \mathrm{E}-10$ & 4.38E-07 & $1.08 \mathrm{E}-08$ \\
\hline 0.8 & $2.66 \mathrm{E}-15$ & $1.78 \mathrm{E}-15$ & $2.15 \mathrm{E}-12$ & $1.97 \mathrm{E}-10$ & $3.20 \mathrm{E}-07$ & $7.85 \mathrm{E}-09$ \\
\hline 0.9 & $1.33 \mathrm{E}-15$ & $4.44 \mathrm{E}-16$ & $1.15 \mathrm{E}-13$ & $1.05 \mathrm{E}-11$ & $1.69 \mathrm{E}-07$ & $4.12 \mathrm{E}-09$ \\
\hline
\end{tabular}


Table 7: Absolute error comparison of LWCM when $k=1$

\begin{tabular}{|c|c|c|c|c|}
\hline$x_{i}$ & LWCM & & & DTM [13] \\
\hline & $M=18$ & $M=16$ & $M=14$ & \\
\hline 0.1 & $1.25 \mathrm{E}-16$ & $9.71 \mathrm{E}-17$ & 7.49E-15 & $7.51 \mathrm{E}-14$ \\
\hline 0.2 & $1.11 \mathrm{E}-16$ & 0.000000 & $2.37 \mathrm{E}-13$ & $2.77 \mathrm{E}-12$ \\
\hline 0.3 & $5.55 \mathrm{E}-17$ & 7.77E-16 & $1.23 \mathrm{E}-12$ & $1.73 \mathrm{E}-11$ \\
\hline 0.4 & 0.000000 & $2.05 \mathrm{E}-15$ & $2.76 \mathrm{E}-12$ & $5.02 \mathrm{E}-11$ \\
\hline 0.5 & $5.55 \mathrm{E}-17$ & $2.72 \mathrm{E}-15$ & $3.54 \mathrm{E}-12$ & $9.34 \mathrm{E}-11$ \\
\hline 0.6 & $5.55 \mathrm{E}-17$ & $2.00 \mathrm{E}-15$ & $2.77 \mathrm{E}-12$ & $1.28 \mathrm{E}-10$ \\
\hline 0.7 & $5.55 \mathrm{E}-17$ & $7.77 \mathrm{E}-16$ & $1.24 \mathrm{E}-12$ & $1.39 \mathrm{E}-10$ \\
\hline 0.8 & $1.11 \mathrm{E}-16$ & $1.11 \mathrm{E}-16$ & $2.39 \mathrm{E}-13$ & $1.23 \mathrm{E}-10$ \\
\hline 0.9 & $1.67 \mathrm{E}-16$ & $4.44 \mathrm{E}-16$ & $8.22 \mathrm{E}-13$ & $7.50 \mathrm{E}-11$ \\
\hline
\end{tabular}

Table 8: Absolute error comparison of LWCM when $k=1$

\begin{tabular}{|c|c|c|c|c|}
\hline$x_{i}$ & LWCM & & & DTM [13] \\
\hline & $M=18$ & $M=16$ & $M=14$ & \\
\hline 0.1 & $3.55 \mathrm{E}-15$ & $3.05 \mathrm{E}-12$ & $1.94 \mathrm{E}-09$ & $1.61 \mathrm{E}-07$ \\
\hline 0.2 & $6.77 \mathrm{E}-15$ & $5.80 \mathrm{E}-12$ & 3.70E-09 & $3.07 \mathrm{E}-07$ \\
\hline 0.3 & $9.21 \mathrm{E}-15$ & 7.99E-12 & 5.09E-09 & $4.22 \mathrm{E}-07$ \\
\hline 0.4 & $1.09 \mathrm{E}-14$ & $9.39 \mathrm{E}-12$ & $5.98 \mathrm{E}-09$ & 4.97E-07 \\
\hline 0.5 & $1.15 \mathrm{E}-14$ & $9.87 \mathrm{E}-12$ & $6.29 \mathrm{E}-09$ & $5.22 \mathrm{E}-07$ \\
\hline 0.6 & $1.08 \mathrm{E}-14$ & $9.39 \mathrm{E}-12$ & $5.98 \mathrm{E}-09$ & $4.96 \mathrm{E}-07$ \\
\hline 0.7 & $9.27 \mathrm{E}-15$ & 7.99E-12 & $5.09 \mathrm{E}-09$ & $4.22 \mathrm{E}-07$ \\
\hline 0.8 & $6.77 \mathrm{E}-15$ & $5.80 \mathrm{E}-12$ & $3.70 \mathrm{E}-09$ & $3.07 \mathrm{E}-07$ \\
\hline 0.9 & $3.72 \mathrm{E}-15$ & $3.05 \mathrm{E}-12$ & 1.94E-09 & $1.61 \mathrm{E}-07$ \\
\hline
\end{tabular}




\section{CONCLUSION}

The Legendre wavelet collocation method is used to solve linear and nonlinear boundary value problems of orders eighth, tenth, and twelve in this work. The results obtained are compared with the results of QBSM, NIM, DTM and other method in $[2,8,12,27]$ from the available literature. It has been observed that the results of the proposed method are efficient, accurate, easy to apply, and needs less computational cost. The technique can be applied to partial [38], integral [39], and fractional differential equations [40] easily.

\section{DECLARATIONS}

Funding: Not applicable

Conflicts of interest/Competing interests:

The authors declare no conflict of interest

Data availability: Not applicable

Code availability: Not applicable

Authors' contributions:

Siraj ul Haq: Original draft write up and Supervision

Muhammad Sohaib: Conceptualization,

Methodology, Reviewing and Editing.

\section{REFERENCES}

[1] R. P. Agrawal, Boundary Value Problems for Higher Ordinary Differential Equations, World Scientific, Singapore, (1986).

[2] G. Akram and H. Rehman, Numerical solution of Eighth order boundary value problems in reproducing kernel space, Numer. Algorithms 62 (2013), pp. 527-540.

[3] A. Boutayeb and E. H. Twizell, Finite difference methods for Twelfth-order, J. Comput. Appl. Math. 35 (1991), pp. 133-138.

[4] S. Chandrasekhar, Hydrodynamic and
Hydromagnetic Stability, Dover, New York, (1981).

[5] A. K. Dizicheh, F. Ismail, M. T. Kajani, and M. Maleki, A Legendre wavelet spectral collocation method for solving Oscillatory initial value problems, J. Appl. Math.

http://dx.doi.org/10.1155/2013/591636.

[6] F. Geng and X. Li, Variational iteration method for solving Tenth-order boundary value problems, Math. Sci. 3 (2009), pp. 161-172.

[7] Sohaib M, Haq S. An efficient wavelet-based method for numerical solution of nonlinear integral and integro-differential equations. Math Meth Appl Sci. (2020), pp. 1-15.

[8] A. Golbabai and M. Javidi, Application of Homotopy perturbation method for solving Eighthorder boundary value problems, Appl. Math. Comput. 191 (2007), pp. 334-346.

[9] J. S. Guf and W. S. Jiang, The Haar wavelets operational matrix of integration, Internat. J. Systems Sci. 27 (1996), pp. 623-628.

[10] M. S. Hafshejani, S. K. Vanani, and J. S. Hafshejani, Numerical solution of Delay differential equations using Legendre wavelet method, World Appl. Sci. J. 13 (2011), pp. 27-33.

[11] S. Haq, M. Idrees, and S. U. Islam, Application of Optimal Homotopy asymptotic method to Eighth order initial and boundary value problems, Int. J. Appl. Math. Comput. 2 (2010), pp. 73-80.

[12] J. H. He, The variational iteration method for eighth-order initial-boundary value problems, Phys. Scr. 76 (2007), pp. 680-682. 
[13] S. U. Islam, S. Haq, and J. Ali, Numerical solution of special 12th-order boundary value problems using Differential transform method, Commun. Nonlinear Sci. Numer. Simul. 14 (2009), pp. 1132-1138.

[14] M. Inc, D.J. Evans, An efficient approach to approximate solutions of eighth order boundary value problems, Int. J. Comput. Math. 81 (2004), pp. 685-692.

[15] A. S. V. R. Kanth and K. Aruna, Variational iteration method for Twelfth-order boundary-value problems, Comput. Math. Appl. 58 (2009), pp. 2360-2364.

[16] S. Hussain, A. Shah, S. Ayub and A. Ullah, An approximate analytical solution of the Allen-Cahn equation using homotopy perturbation method and homotopy analysis method, Helion 5 (12), (2019),

https://doi.org/10.1016/j.heliyon.2019.e03060.

[17] A. A. Kurdi and S. Mulhem, Solution of Twelfth order boundary value problems using Adomian decomposition method, J. Appl. Sci. Res. 7 (2011), pp. $922-934$.

[18] G. R. Liu and T. Y. Wu, Differential quadrature solutions of Eighth-order boundary-value differential equations, J. Comput. Appl. Math. 145 (2002), pp. 223-235.

[19] H. Mirmoradi, H. Mazaheripour, S. Ghanbarpour, and A. Barari, Homotopy perturbation method for solving Twelfth order boundary value problems, Int. J. of Res. and Rev. in Appl. Sci. 1 (2009), pp. 163-173.
[20] S. Hussain and A. Shah, Solution of generalized Drinfeld-Sokolov equations by using homotopy perturbation method and variational iteration method, Math. Rep., pp. 49-58, (2013).

[21] M. A. Noor, S. T. Mohyud-Din, Variational iteration decomposition method for solving eighthorder boundary value problems, Differ. Equat. Nonlinear Mech. (2007), doi:10.1155/2007/19529.

[22] M. I. A. Othman, A. M. S. Mahdy, and R. M. Farouk, Numerical solution of 12th order boundary value problems by using Homotopy perturbation method, J. Math. Comput. Sci. 1 (2010), pp. 14-27.

[23] J. Rashidinia, R. Jalilian, and K. Farajeyan, Non polynomial spline solutions for special linear Tenthorder boundary value problems, W. J. Mod. Simul 7 (2011), pp. 40-51.

[24] A. Shah and A. A. Siddiqui, Variational iteration method for the solution of viscous CahnHilliard equation, World Appl. Sci. J., (2012), pp. 1589-1592.

[25] M. Razzaghi and S. Yousefi, The Legendre wavelets operational matrix of integration, Int. J. Sys. Sci. 32 (2001), pp. 495-502.

[26] S. S. Siddiqi and M. Iftikhar, Numerical solution of higher order boundary value problems, Abstr. Appl. Anal. (2013),

http://dx.doi.org/10.1155/2013/427521.

[27] S. S. Siddiqi, G. Akram, Solution of eighth-order boundary value problems using the nonpolynomial spline technique, Int. J. Comput. Math. 84 (3) (2007), pp. 347-368. 
[28] S. S. Siddiqi and G. Akram, Solution of 10thorder boundary value problems using nonpolynomial spline technique, Appl. Math. Comput. 190 (2007), pp. 641-651.

[29] S. S. Siddiqi and G. Akram, Solutions of Tenthorder boundary value problems using Eleventh degree spline, Appl. Math. Comput. 185 (2007), pp. 115-127.

[30] S. S. Siddiqi and A. Ghazala, Solutions of Twelfth order boundary value problems using Thirteen-degree spline, Appl. Math. Comput. 182 (2006), pp. 1443-1453.

[31] I. Ullah, H. Khan, and M. T. Rahim, Numerical solutions of higher order non-linear boundary value problems by New iterative method, Appl. Math. Sci. 7 (2013), pp. 2429-2439.

[32] S. G. Venkatesh, S. K. Ayyaswamy, and S. R. Balachandar, Legendre wavelets-based approximation method for solving Advection problems, A. S. Eng. J. 4 (2013), pp. 925-932.

[33] K. N. S. K. Viswanadham and Y.S. Raju, Quintic B-spline collocation method for Eighth order boundary value problems, Adv. Comput. Math. Appli. 1 (2012).

[34] A. M. Wazwaz, Approximate solutions to boundary value problems of higher order by the Modified decomposition method, Compu. Math Appli. 40 (2000), pp. 679-691.
[35] S. A. Yousefi, Legendre wavelets method for solving differential equations of Lane Emden type, Appl. Math. Comput. 181 (2006), pp. 1417-1422.

[36] E. Yusufoglu, New solitonary solutions for the MBBN equations using Exp function method, Phys. Lett. A 2007.

[37] S. S. Bayin, Mathematical Methods in Science and Engineering. Wiley. ch. 2. ISBN 978-0-47004142-0 (2006).

[38] S. Singh, V. K. Patel, V. Singh, Application of wavelet collocation method for hyperbolic partial differential equations via matrices, Appl. Math. Comput. 320: 407-424, (2018).

[39] N. Khorrami, A. S. Shamloo, and P. B. Moghaddam, Numerical Solution of Interval Volterra-Fredholm-Hammerstein Integral Equations via Interval Legendre Wavelets Method. International Journal of Industrial Mathematics, 13(1), pp.15-28 (2021).

[40] Yuttanan, Boonrod, Razzaghi, Mohsen \& Vo, Thieu. Legendre wavelet method for fractional delay differential equations. Appl Numer Math. 168. 10.1016/j.apnum.2021.05.024 (2021).

[41] M. Paliivets, E. Andreeve, A. Bakshtanin, D. Benin, and V. Snezhko, New iterative method for solving nonlinear equations in fluid mechanics, Int. J. Appl. Mech. Engg. pp. 163-174, DOI: 10.2478/ijame-2021-0042. 
[42] A. Shah, S. Khlil, and S. Hussain, An efficient iterative technique for solving some nonlinear problems, Int. J. of Nonlinear Science, 13 (1), DOI: IJNS.2012.02.15/583.
[43] A. M. Siddiqui, A. Shah, and Q. K. Ghori, Homotopy Analysis of Slider bearing Lubricated with Powell-Eyring fluid, J. Appl. Sci., (2006), pp. 2358-2367.

Received: 26 Aug. 2021. Revised/Accepted: 13 Dec. 2021. 